\title{
En torno al viaje en avión en la Argentina: representaciones y experiencias, 1929-1958
}

\author{
Commercial air travel in Argentina: \\ representations and experiences, 1929-1958
}

\author{
Melina Piglia \\ Consejo Nacional de Investigaciones Científicas y Técnicas \\ Centro de Estudios Históricos \\ Universidad Nacional de Mar del Plata \\ (Argentina) \\ pigliamelina@gmail.com
}

Este trabajo se centra en la construcción del viaje aéreo como consumo en la Argentina durante la era previa a la introducción de los aviones a reacción, explorando tres cuestiones. En la primera sección, se analizan los fundamentos del transporte de pasajeros en la Argentina, la transformación de las aeronaves que permitió aumentar su carga útil y lo hizo, por lo tanto, posible, y el despliegue de este proceso, marcado por el incremento de la oferta de asientos/kilómetro y el sostenido crecimiento del transporte de pasajeros. La siguiente indaga en la propia práctica del viaje en avión, una novedosa experiencia (que se modificó al modificarse la técnica) para quienes volaban, que debieron aprender las disposiciones corporales y de conducta necesarias para ser pasajeros; se consideran también otros dispositivos de regulación de la conducta que contribuyeron a construir a la práctica y a los pasajeros como tales. Finalmente se estudian las representaciones sociales en torno al viaje en avión, que lo construyeron como una práctica prestigiosa, segura, deseable, moderna, emocionante y distinguida entre quienes volaban y también entre quienes jamás podrían hacerlo, generando una amplia adhesión social a la aviación, llamada en la época: "conciencia aeronáutica".

Palabras Clave: Consumo - Aviación comercial - Viaje - Aeromovilidad 


\begin{abstract}
This work explores the construction of air travel as a practice of consumption in Argentina before the implementation of the jet. First, it addresses the material aspects of air passenger transport, focusing on the development of the aircraft, and, how it led a sharp increase of seats per kilometer and, in turn, a growth of the number of passengers. Then, the work explores the air travel, looking at embodied practices of travelling triggered by the novel experience of flying; it also discusses how this practice was transforming over time and focuses on norms and disciplinary practices which shaped people behaviors creating a new kind of passenger: the air traveler. Finally, the paper examines the emergence of social representations about air travel as a safe, desirable, modern, exciting, and distinguished travel creating a broad social acceptance of aviation, named at that time as "aviation awareness", among those who could and could not experience the air.
\end{abstract}

Key Words: Consumption - Commercial aviation - Travel - Aeromobility

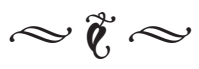

\section{Introducción}

En sus albores, el vuelo en avión fue visto como un deporte, un espectáculo, un juguete exótico o un arma. Sin embargo, con el paso del tiempo, fue ganando espacio como medio de transporte de correspondencia y luego, desde fines de los años veinte, también de pasajeros.

Este trabajo indaga en la construcción del viaje aéreo como consumo en la Argentina en la era previa a la introducción de los aviones a reacción en 1959. Se trata de años clave en la conformación de la aeronavegación comercial en la Argentina, en los que surgieron las primeras aerolíneas comerciales, se construyó la infraestructura básica -aeropuertos, torres de radio, rutas aéreas-, se conformó un sistema de formación local de los trabajadores del aire y se fijaron los procedimientos de seguridad de la aeronavegación. Pero, además, sostendremos que se trata del período en el que se sentaron las bases culturales del viaje aéreo, a partir de la construcción de una amplia aceptación social de la aviación, de la práctica del viaje aéreo y de sus sujetos, los pasajeros.

Nos proponemos analizar el viaje en avión pensándolo como consumo. Desde los años '80, este último se ha transformado en objeto de estudio para las ciencias sociales, que han destacado la importancia de sus dimensiones simbólicas, junto a las económicas o materiales. ${ }^{1} \mathrm{La}$ emergencia de un campo

1. Véase por ejemplo, BOCOCK, Robert, El Consumo, 
específico dentro de la historiografía argentina, es más reciente. La historia del consumo -de bienes, de viviendas o de experiencias (como el turismo, los espectáculos deportivos o el teatro)- ha sido un terreno fértil para que algunos investigadores se dedicaran a indagar en la cuestión de la modernización de la cultura y la sociedad argentina, ligada a los procesos de movilidad social o a analizar el impacto simbólico y material del peronismo. ${ }^{2}$

Nuestra mirada del surgimiento del viaje en avión como consumo abreva también en los estudios sobre la movilidad, que se han multiplicado en la última década revolucionando la mirada sobre los transportes. ${ }^{3}$ Esta aproximación pone el foco en el carácter móvil de la sociedad moderna y contempla al movimiento en sí mismo como un objeto relevante de análisis. Dentro de este campo, los estudios dedicados a la historia de la aeromovilidad continúan siendo

Talasa, Madrid, 1993; APPADURAI, Arjun (editor) La vida social de las cosas. Perspectiva Cultural de las mercancias, Grijalbo, México, 1986.

2. Véase por ejemplo PASTORIZA, Elisa, La conquista de las vacaciones. Breve historia del turismo en la Argentina, Edhasa, Buenos Aires, 2011; PÉREZ, Inés, El hogar tecnificado, Biblos, Buenos Aires, 2013; PIGLIA, Melina, Autos, rutas y turismo. El Automóvil Club Argentino y el Estado, Siglo XXI, Buenos Aires, 2014; ROCCHI, Fernando, "Inventando la soberanía del consumidor: publicidad, privacidad y revolución del mercado en Argentina, 1860-1940", en DEVOTO, Fernando y MADERO, Marta (directores) Historia de la vida privada en Argentina, T. II, Taurus, Buenos Aires, 1999; MILANESIO, Natalia, Cuando los trabajadores salieron de compras. Nuevos consumidores, publicidad y cambio cultural durante el primer peronismo, Siglo XXI, Buenos Aires, 2014.

3. Véase CWERNER, Saulo, "Introducing Aeromobilities", en CWERNER, Saulo, KESSERLING, Sven y URRY, John (editores) Aeromobilities, Rutledge, Nueva York, 2009. marginales, y esto es particularmente agudo en la historiografía latinoamericana en general, $\mathrm{y}$ argentina en particular. ${ }^{4}$ Algunas notables excepciones implican, sin embargo, avances en este sentido: así, por ejemplo, Anahí Ballent ha explorado la producción de aeroespacios y su consumo como paisaje y entretenimiento, en su estudio sobre la operación territorial involucrada en la construcción del Aeropuerto Internacional de Ezeiza. ${ }^{5}$

E1 presente artículo pretende explorar tres cuestiones. En la primera sección, se analizan los fundamentos del transporte de pasajeros, sus condiciones técnicas y materiales, siguiendo el despliegue del fenómeno del viaje. La siguiente indaga en la propia práctica de la travesía en avión, en las experiencias de quienes vuelan y en la forma en que esas experiencias y otros dispositivos de regulación de la conducta fueron construyendo discursivamente a la práctica y a los pasajeros como tales. Finalmente, buscaremos estudiar las representaciones sociales en torno al viaje aéreo, en especial la configuración de lo que en la época se llamaba una "conciencia aeronáutica”. Consideramos que el análisis del caso argentino puede contribuir a ampliar el debate en torno a la relación entre cultura y tecnologías, contrastando las formas en que éstas se experimentaron en su centro productor y en los países periféricos que las adoptaban y adaptaban.

4. Véase BEDNAREK, Janet R., "Open Sky: The Broad Range of Recent Scholarship in Aviation History", en Movilidad en la Historia, Anuario de la Asociación Internacional de Historia del Transporte, el Tráfico y la Movilidad, Philadelphia, 2013, V.IV.

5. Véase BALLENT, Anahí, "El peronismo y sus escenarios. La operación territorial de Ezeiza (19441955)", en Entrepasados, Buenos Aires, 2002, № 22. 
Como para muchos temas de la historia argentina contemporánea, las fuentes son escasas y fragmentarias, en particular a la hora de reconstruir prácticas concretas y experiencias. En los estudios sobre aviación, el fenómeno se ve agravado por el impacto del proceso de privatización de Aerolíneas Argentinas en los años noventa, que derivó en la pérdida de buena parte del archivo. Hemos trabajado con materiales provenientes de las memorias de algunas de estas empresas, de informes de la Dirección de Aviación Civil, de revistas editadas por las aerolíneas, folletos y prensa en general, así como con algunas entrevistas a quienes se desempeñaron como azafatas y pilotos en este período temprano. Procurando darle cierta coherencia al corpus, nos hemos concentrado en las líneas aéreas que operaban destinos dentro del territorio argentino.

\section{La aviación comercial en Argentina y el transporte de pasajeros}

\section{La etapa pionera (1929-1938)}

La Primera Guerra Mundial significó un gran impulso para el desarrollo de la aviación. Terminado el conflicto, ese impulso se volcó hacia la aviación comercial, que podía brindar una salida para las industrias aeronáuticas europeas y norteamericanas y dar empleo a los pilotos. Las primeras rutas aerocomerciales regulares para el transporte de correspondencia y pasajeros se establecieron en Europa en 1919: para 1923 ya operaban una veintena de compañías. $^{6}$ Latinoamérica aparecía

6. En los Estados Unidos, las aerolíneas comenzaron a desarrollarse a partir de 1925, cuando la legislación autorizó al correo a establecer convenios de distribución como un mercado con enorme potencial, en particular porque en buena parte de sus territorios las comunicaciones de superficie estaban poco desarrolladas. Italia, Alemania, Francia y, bastante más tarde, Estados Unidos comenzaron entonces una competencia que se haría cada vez más aguda por el control de las rutas aéreas latinoamericanas. ${ }^{7}$

Desde 1919, llegaron así las “misiones” aéreas (francesa, italiana, alemana) a la Argentina, destinadas a mostrar las posibilidades de los nuevos aviones, sobre todo, para el transporte de correo. La Argentina resultaba una plaza potencialmente muy atractiva. Por un lado, había alcanzado tasas muy elevadas de crecimiento y parecía brindar apetecibles oportunidades comerciales. Por otra parte, se trataba de un país sumamente extenso, con baja densidad de población y con amplias zonas en relativo aislamiento. Los caminos de tránsito permanente fueron muy escasos hasta la segunda mitad de los años treinta y las comunicaciones terrestres estaban dominadas por el ferrocarril, que cubría con más densidad la región pampeana y conectaba las principales ciudades del centro y norte del país con la capital, Buenos Aires, donde en 1914 residía el $25 \%$ de la población y tenía lugar la principal actividad política, comercial y financiera. La

de correspondencia con líneas aéreas privadas. Pero la aviación comercial norteamericana recuperaría rápidamente el terreno perdido en los años treinta. Véase por ejemplo: MASEFIELD, Peter, MASEFIELD, Peter, "From Paris to Chicago. The Civilisation of Air Transport", en The Putnam Aeronautical Review, Londres, 1990, V. II, pp. 18-23.

7. Cfr. PHILLIPS NEWTON, Wesley, "International Aviation Rivalry in Latin America, 1919-1927", en Journal of Inter-American Studies, 1965, V. VII, No 3, pp. 346-352. HAGEDORN, Dan, Conquistadors of the Sky. A History of Aviation in Latin America, Florida University Press, Gainsville, 2010. 
Patagonia, con su crecientemente próspera economía basada en la ganadería ovina y la extracción de petróleo, se comunicaba con Buenos Aires casi exclusivamente por mar, mientras el extremo noreste dependía sobre todo del transporte fluvial. ${ }^{8}$

En ese marco, en 1924, se dieron los primeros pasos para el establecimiento de una línea aérea en el país. Una empresa francesa envío una misión a Brasil con el objeto de estudiar el establecimiento de un servicio aeropostal con Europa, con cabecera en Buenos Aires y con escala en Natal. Tras obtener un convenio de exclusividad con el Correo Argentino, esos capitales constituyeron Aeroposta Argentina S.A., la primera línea aérea local, a fines de 1927. ${ }^{9}$ La filial local comenzó a volar en 1929 la ruta Buenos Aires-Asunción (correo y pasajeros) y luego inauguró la línea al sur, entre Bahía Blanca y Comodoro Rivadavia, con conexión por ferrocarril a Buenos Aires, que en abril de 1930 se extendió hasta Río Gallegos. En el verano 1929-1930, se realizaron también vuelos a Mar del Plata. ${ }^{10}$ Aeroposta utilizaba inicialmente aviones Latécoère que podían llevar entre cinco y ocho pasajeros. Tenían un instrumental muy básico y se volaba bajo, siguiendo las referencias del paisaje; los accidentes, algunos fatales, eran frecuentes. ${ }^{11}$

8. Ligada a ambas actividades y localizada en la costa de la provincia de Chubut la ciudad y puerto de Comodoro Rivadavia era la más poblada de la Patagonia.

9. Se trataba de la Compagnie Generale D'Entreprises aeronautiques de Pierre G. Latécoère, Véase Centro Argentino de Estudios Históricos Aerocomerciales, La Aeroposta Argentina y sus orígenes, 1927-1987, Buenos Aires, 2010.

10. Véase "En la línea regular de la Patagonia han viajado cerca de mil personas", Revista Aero, 1930, o 9, p.7.

11. Véase La Aeroposta..., 1927-1987, Op. Cit., pp. 2-5.
En 1929, comenzaron a operar en la Argentina dos empresas norteamericanas, Nyrba (New York Río and Buenos Aires Line) y Panagra (Pan American Grace Airways). A fines de aquel año, Nyrba volaba a Montevideo, Santiago de Chile y también tenía una ruta a Bolivia, con escalas en el centro y norte del país. Panagra, por su parte, tenía un vuelo semanal a Santiago de Chile que realizaba una escala en Mendoza. ${ }^{12}$

La depresión económica internacional que había comenzado en 1930 afectó profundamente a las empresas aéreas, agudizando el déficit operativo característico de la actividad aerocomercial en todo el mundo en esta etapa. A fines de 1930, Nyrba fue absorbida por Pan American Airways, que ya controlaba Panagra. Aeroposta atravesó una crisis financiera, por la liquidación de la empresa matriz francesa, y quedó reducida a su ruta a la Patagonia.

La consolidación del avión como medio de transporte de pasajeros en la Argentina (1938-1958)

Durante los años treinta los avances de la industria aeronáutica, que respondían sobre todo a la presión militar pero se aplicaban a fines civiles, permitieron el desarrollo de aviones más veloces, que poseían sistemas de navegación por radio y podían llevar alrededor de veinte pasajeros.

En la segunda mitad de los años treinta, aviones de este tipo llegaron a la Argentina, donde funcionaban efectivamente dos rutas de

12. Véase "Horarios de las líneas argentinas", en Revista Aero, 1929, № 2, pp. 6-7. 
Imagen 1. Despedida de pasajeros, al fondo, un Junker de Aeroposta.

Fuente: Folleto de Aeroposta, 1942.

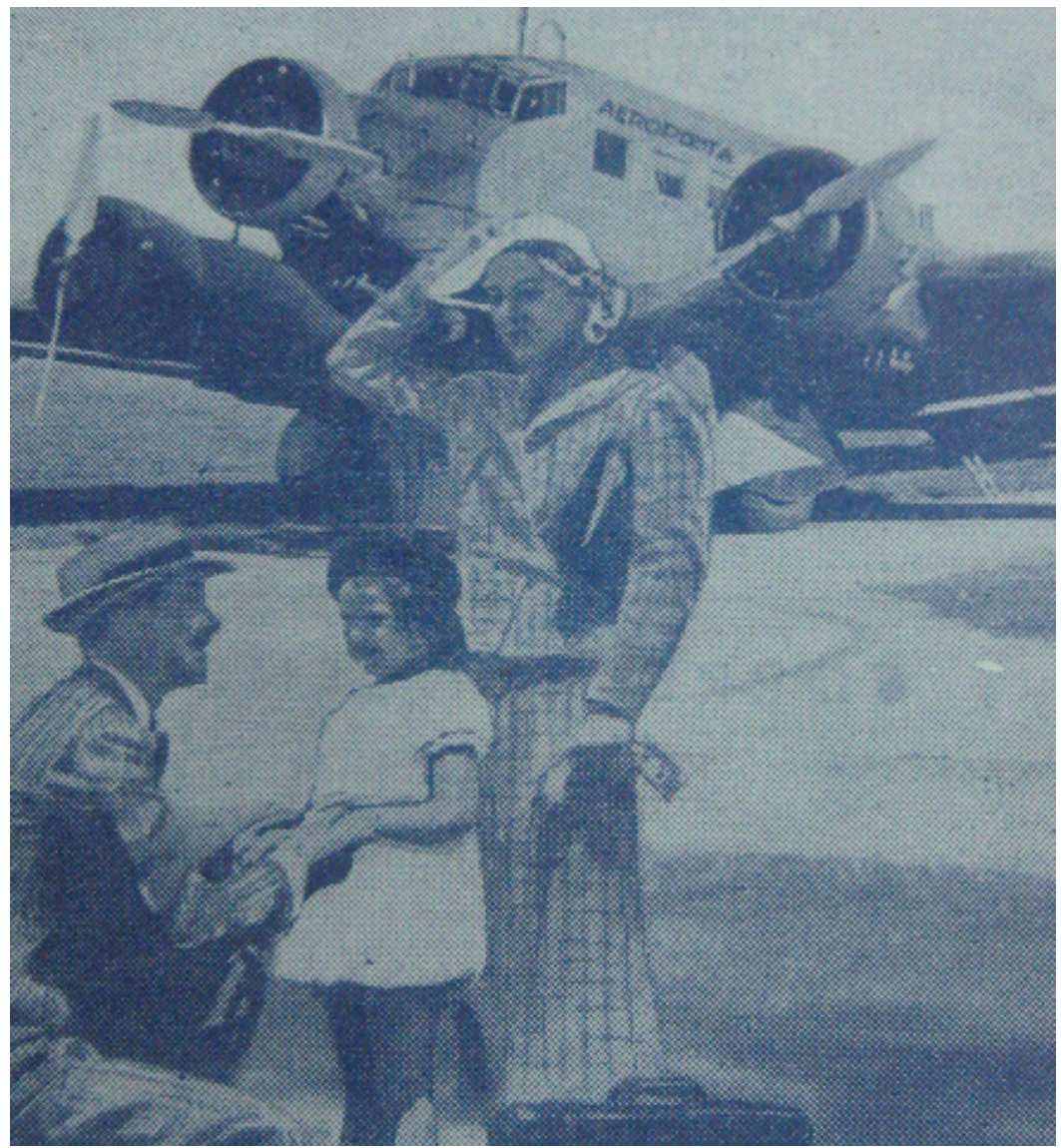

cabotaje: la línea costera al sur de Aeroposta y la que unía Buenos Aires y Santiago de Chile, con conexión a Estados Unidos, que hacía una escala en Mendoza. ${ }^{13}$ A partir de

13. Para 1943, Panagra tenía también un vuelo a Bolivia con escalas en Tucumán y Salta. Si bien Mendoza o Tucumán eran ciudades a las que el ferrocarril llegaba desde fines del siglo XIX, poseían economías muy activas -basadas principalmente en el azúcar y el vino- cuyo principal mercado de consumo era el Litoral, por lo que 138
1938, la ruta de Aeroposta se hizo más extensa (desde Buenos Aires hasta Río Grande) y se incorporaron rutas nuevas: una en la precordillera en el territorio de Santa Cruz y, en el verano de 1944-1945, un servicio a Mar del Plata (Véase mapa 1). ${ }^{14}$

resultaba rentable ofrecer comunicaciones más veloces con Buenos Aires.

14. Véase, Memoria y Balance de Aeroposta Argentina S.A., 
Mapa 1. Las rutas de Aeroposta en 1948.

Fuente: Memoria de la Empresa Mixta Aeroposta, 1948.

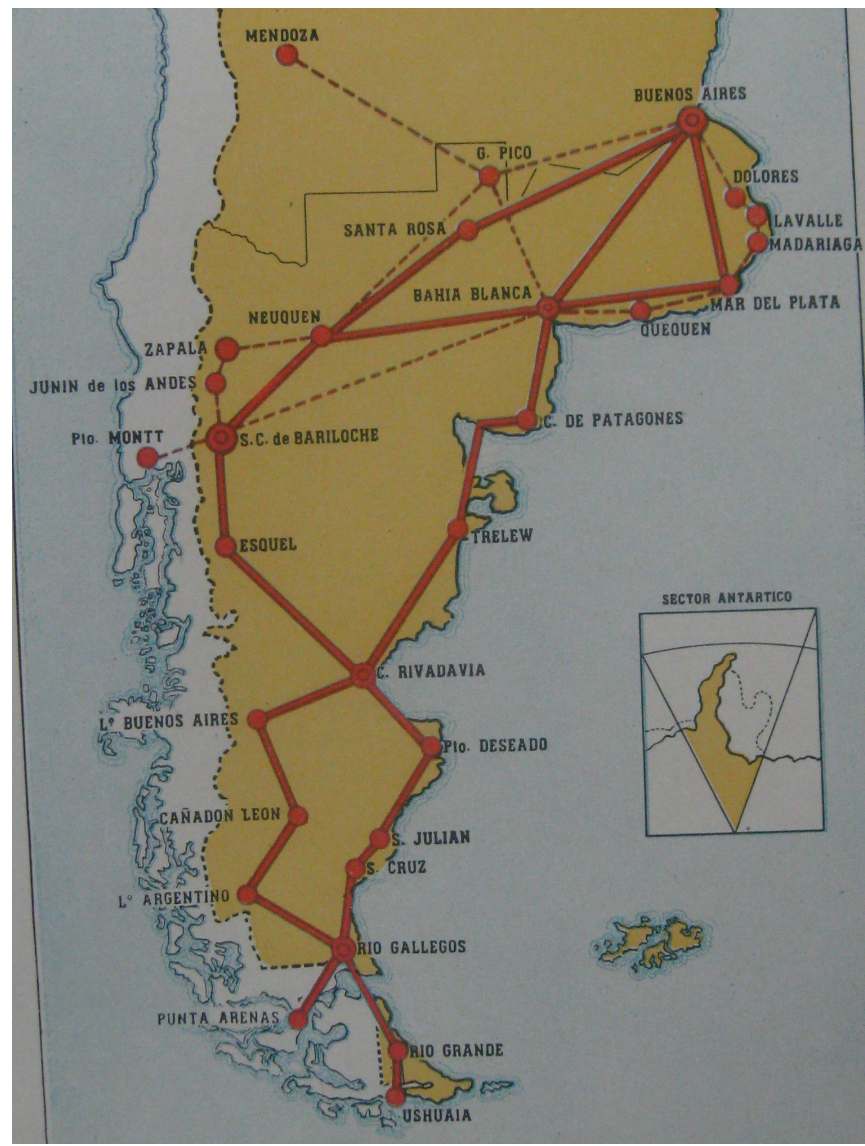

Otras líneas aéreas se abrieron en esos años: la Corporación Sudamericana de Transportes Aéreos (CSTA) (que unía Buenos Aires con la provincia de Santa Fe y el noreste), y las líneas aéreas creadas por el Comando Aéreo del Ejército, la Línea Aérea del Sudoeste (LASO, 1941), la Línea Aérea del Noreste (LANE, 1944) y la línea a Mar del Plata

ejercicio de 1945, p. 2.
(1945), reunidas en 1945 en las Líneas Aéreas del Estado (LADE). El objetivo de LADE era por supuesto desempeñar una función de "fomento", allí donde el capital privado no se interesaba en invertir, pero a la vez tenía una clara función militar, al permitir un mayor conocimiento territorial de áreas fronterizas. ${ }^{15}$

15. Las rutas de LASO y LANE conectaban con la Capital, a regiones fronterizas (la Norpatagonia 
Mapa 2. Las rutas de Aerolineas

Argentinas en 1950.

Fuente: Memoria Aerolíneas Argentinas, 1950.

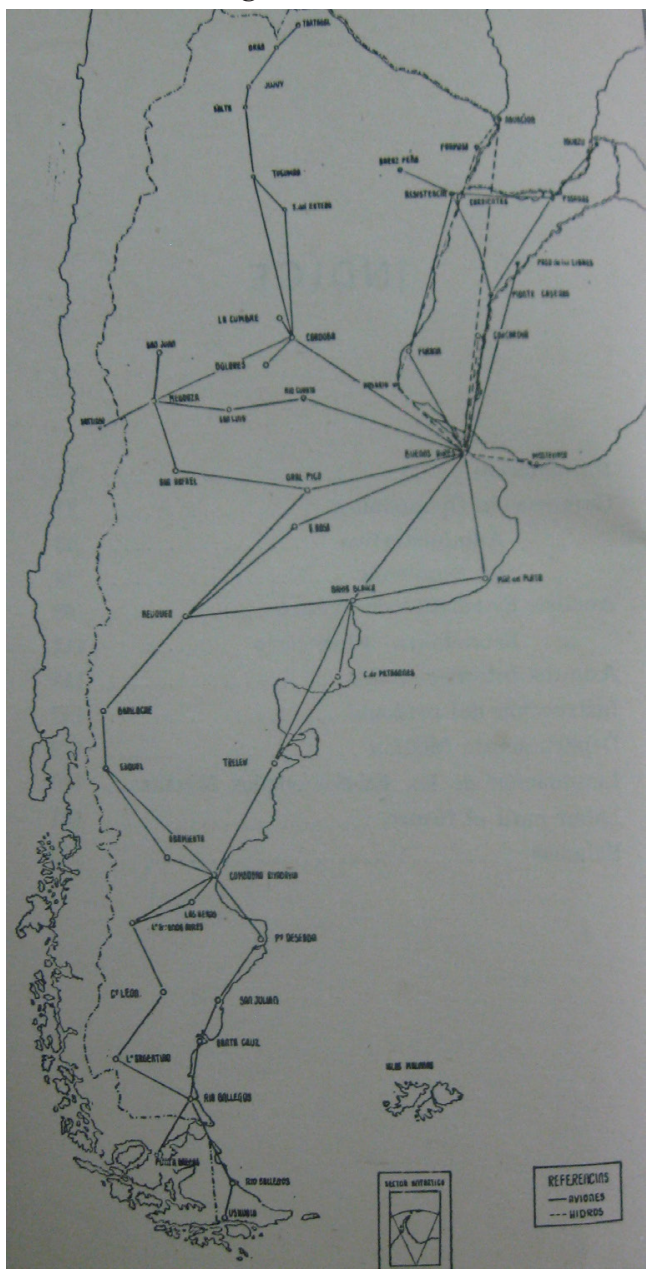

No disponemos de cifras globales sobre el tráfico aéreo en la Argentina para este período, pero algunos datos parciales señalan un impresionante crecimiento de los viajes en avión, que en el caso de Aeroposta se multiplicaron por cien, entre 1935 y $1945 .{ }^{16}$.

En 1945, la situación de las empresas de cabotaje en Argentina sufrió una transformación drástica. Considerado por el gobierno militar como uno de los pilares del "poder aéreo nacional", se nacionalizó toda la infraestructura de tierra (incluyendo las comunicaciones y la meteorología) y se reservó el transporte de cabotaje para empresas estatales o mixtas, en las que los capitales privados solo podían ser argentinos. En 1947, se pusieron en marcha tres empresas mixtas, a las que se les asignaron zonas de influencia, pero para 1949 fueron nacionalizadas y reunidas en una única línea aérea de bandera, Aerolíneas Argentinas, que prácticamente monopolizó el tráfico de cabotaje hasta $1957 .{ }^{17}$

Con Aerolíneas, los aviones y las rutas se multiplicaron (véase mapa 2). La Segunda Guerra había traído una transformación radical en la tecnología aérea, y al terminar el conflicto estuvieron disponibles nuevos aviones para pasajeros más veloces, que podían

andina y el extremo noreste) en las que se temía que la "desconexión” y el atraso pusieran en riesgo la afirmación soberana, pero que a la vez tenían desde hacía unas décadas cierto dinamismo económico (basado en el turismo, el sur, basado en cultivos industriales, el noreste).

16. Véase Memorias y Balances de Aeroposta S.A. 1941, 1942 y 1945.

17. En 1957 el gobierno de facto autorizó la explotación del cabotaje por compañías aéreas privadas y surgieron las empresas Austral, ALA y Transcontinental. 
volar a una altitud mayor y eran más rentables, pero su incorporación en la Argentina fue muy lenta. ${ }^{18}$ Por un lado, porque a la Argentina le resultaba cotoso y difícil adquirir aviones completamente nuevos. ${ }^{19}$ Por el otro, la mayor parte de los aeródromos del país carecían de las pistas duras que necesitaban esos aviones más pesados. ${ }^{20}$

Durante la primera década de existencia de Aerolíneas, los vuelos de cabotaje continuaron efectuándose con aviones relativamente chicos, que volaban bajo, pero que tenían la ventaja de poder aterrizar en aeropuertos más precarios. ${ }^{21}$ A la vez, Aerolíneas mantuvo para el cabotaje un esquema de múltiples escalas, para reducir el peso de combustible y aumentar la carga útil. Ambas situaciones, combinadas, hicieron posible que ciudades pequeñas, gozaran de un servicio aéreo regular que las vinculaba a Buenos

18. Si un DC-3 podía llevar entre 21 y 28 pasajeros y volar a una altura de 1,6 km, el DC-6, (1946), podía llevar entre 48 y 102 pasajeros y casi un 300\% más de peso, tenía una cabina presurizada y podía volar a casi 5 $\mathrm{km}$ de altura. Véase. POTENZE, Luciano, Historia del Transporte Aerocomercial, mimeo, s/n.

19. Las sanciones norteamericanas por la neutralidad argentina en la guerra, se combinaron con las crecientes dificultades de la balanza de pagos. Por otro lado, para la compra de aviones de nueva generación había varios años de espera.

20. El Aeroparque de la ciudad de Buenos Aires fue inaugurado en 1948 y el aeropuerto Internacional de Ezeiza un año después (1949), habiendo empezado su construcción en 1945.

21. Se utilizaban DC-3 y DC-4, hidroaviones Sandringham y Convair 240. En 1948, finalmente llegaron los primeros aviones de nueva generación, los DC-6, pero hasta 1959 se utilizaron en las rutas internacionales. En 1959, llegarían a la Argentina los primeros jets, lo que permitió usar los DC-6 para cabotaje. La etapa que inauguró su introducción, excede sin embargo los propósitos de este trabajo.
Aires y a otras localidades de su región. Los aviones permitían el rápido traslado de quienes viajaban por negocios o trabajo, de los turistas, de aquellos que se dirigían a continuar sus estudios en ciudades más grandes o de pacientes que recibían tratamientos o consultaban especialistas enotras urbes. Igualmente o más importante aún para la vida de esas localidades aisladas, transportaban periódicos, películas, correspondencia, medicamentos, repuestos y otras mercancías, estimulando su vida económica y su integración política y cultural al espacio regional y nacional. ${ }^{22}$

En su primera década, Aerolíneas amplió la oferta de asientos y de destinos, y las cifras de pasajeros en vuelos entre escalas en territorio nacional se multiplicó por $200 .{ }^{23} \mathrm{La}$ expansión del número de usuarios sin embargo se vio probablemente frenada por el alto nivel de las tarifas. Así, en 1941, el costo del vuelo ida y vuelta entre El Palomar y Bariloche (por LASO), equivalía a entre el 77 y el $94 \%$ del salario mensual de un director de escuela en la Capital Federal. ${ }^{24}$

22. La importancia del transporte de mercancías por vía aérea fue aumentando marcadamente en los años cuarenta y cincuenta.

23. Véase MINISTERIO DE GUERRA, Estadística de vuelos entre escalas, Complemento de la Memoria de la Dirección General de Aeronáutica Civil, Ministerio de Guerra, 1943. Archivo de la Dirección de Estudios Históricos de la FA folios 2, 3 y 4; Memoria de Aerolíneas Argentinas correspondiente a 1959, p. 7.

\section{Véase MINISTERIO DE CULTURA Y}

EDUCACIÓN, "Evolución de los salarios docentes. 1906-1975”, 1976, pp. 6 y 11; disponible en: <http:// repositorio.educacion.gov.ar/dspace/bitstream/ handle/123456789/91821/EL001296.pdf?sequence=1 > [Consulta: 23-3-2015] 


\section{La experiencia de volar: cuerpos aéreos}

Los cambios técnicos en los aviones y el desarrollo de las aerolíneas transformaron la experiencia de pasajeros y pilotos. Durante los primeros años, hasta mediados de los años treinta, volar resultaba para los escasos pasajeros una experiencia físicamente desafiante. Los aviones eran muy reducidos, vibraban y se sacudían, el sonido de las hélices era estruendoso. La relación con el medio, el aire con sus densidades y el viento, la percepción en el cuerpo del esfuerzo de los motores, formaba parte de la experiencia de los pilotos, pero también de los pasajeros..$^{25}$ "Es una extraña impresión por cierto- narraba Henri Tracol, escritor y viajero, respecto de su vuelo a la Patagonia en 1937 en un Latte- la que experimenta el pasajero, huésped pasivo en esa lucha con el elemento, fuerza brutal insaciable, aunque desde la cabina, ni el rugir de ese viento puede ser oído: el trepidante rumor de los motores lo cubre...". ${ }^{26}$ Los pasajeros se sentaban en butacas, iban sueltos y debían agarrarse de los asientos en caso de turbulencia y en los despegues y acuatizajes o aterrizajes, para evitar golpearse (véase imagen 2). No había sanitarios ni se servían refrigerios, pero la escasa autonomía de las aeronaves obligaba a paradas frecuentes, en las que todo el pasaje descendía.

La experiencia, aunque exigente, era embriagadora: la mirada del pájaro que

25. Véase por ejemplo LURO CAMBACERES, Rufino, Rumbo $180^{\circ}$. Huellas en el cielo austral, Buenos Aires, 1956.

26. "En avión hacia Tierra del Fuego", en Revista Aeroposta, 1938, № 2, p. 14.

142 convierte a los espacios sobrevolados en paisajes sublimes. ${ }^{27}$ Los pasajeros se convertían, como sostiene Gordon Pirie respecto quienes volaban a través del Imperio Británico en los años treinta, en turistas sin intención de serlo; la baja altura, la necesidad de volar de día, las largas horas (unas 15, por ejemplo desde Bahía Blanca a Río Grande en 1937) permitían apreciar un espacio al que el distanciamiento volvía paisaje e incluir el goce estético en vuelos que, en general, no tenían una finalidad turística. ${ }^{28}$ Así, Tracol transmite el disfrute de los placeres estéticos de su vuelo sobre la costa Patagónica, el encuentro con un paisaje que describía como casi onírico: "Los primeros contrafuertes de la Patagonia alinean sus defensas, tortuosas, batidas incesantemente por las olas, a los pies de un paisaje montañoso atormentado, que asombra. Ese paisaje parece un sueño; a veces una pesadilla por su similitud con un desastre geológico, ¡pero qué grandeza hay en él!". Hasta los pozos petroleros y la actividad mercantil de la "metrópoli" patagónica (Comodoro Rivadavia) quedan estetizados por la distancia de la mirada área: "Este desierto erizado de frágiles esqueletos de acero, da la sensación de un dibujo trazado por un loco". ${ }^{29}$

Enladécada delveintey del treintala aviación, ese novedoso "experimento", concitaba gran atención. La prensa popular, que conoció una etapa particularmente prolífica, acompañaba

27. El paisaje es un espacio encuadrado por el hombre; implica siempre una selección y otras operaciones de representación. Véase: ALIATA, Fernando y SILVESTRI, Graciela, El paisaje en el arte y las ciencias bumanas, CEAL, Buenos Aires, 1994, pp. 7-17.

28. Véase PIRIE, Gordon, "Incidental Tourism: British Imperial air travel in the 1930's", en Journal of Tourism History, Preston, 2009, V. 1, № 1.

29. “En avión...”, Op. Cit., p 15. 
Imagen 2. Rutas y horarios de Panagra en 1930.

Fuente: <http://www.timetableimages.com/ttimages/pg3001.htm> [Consulta: marzo de 2015].
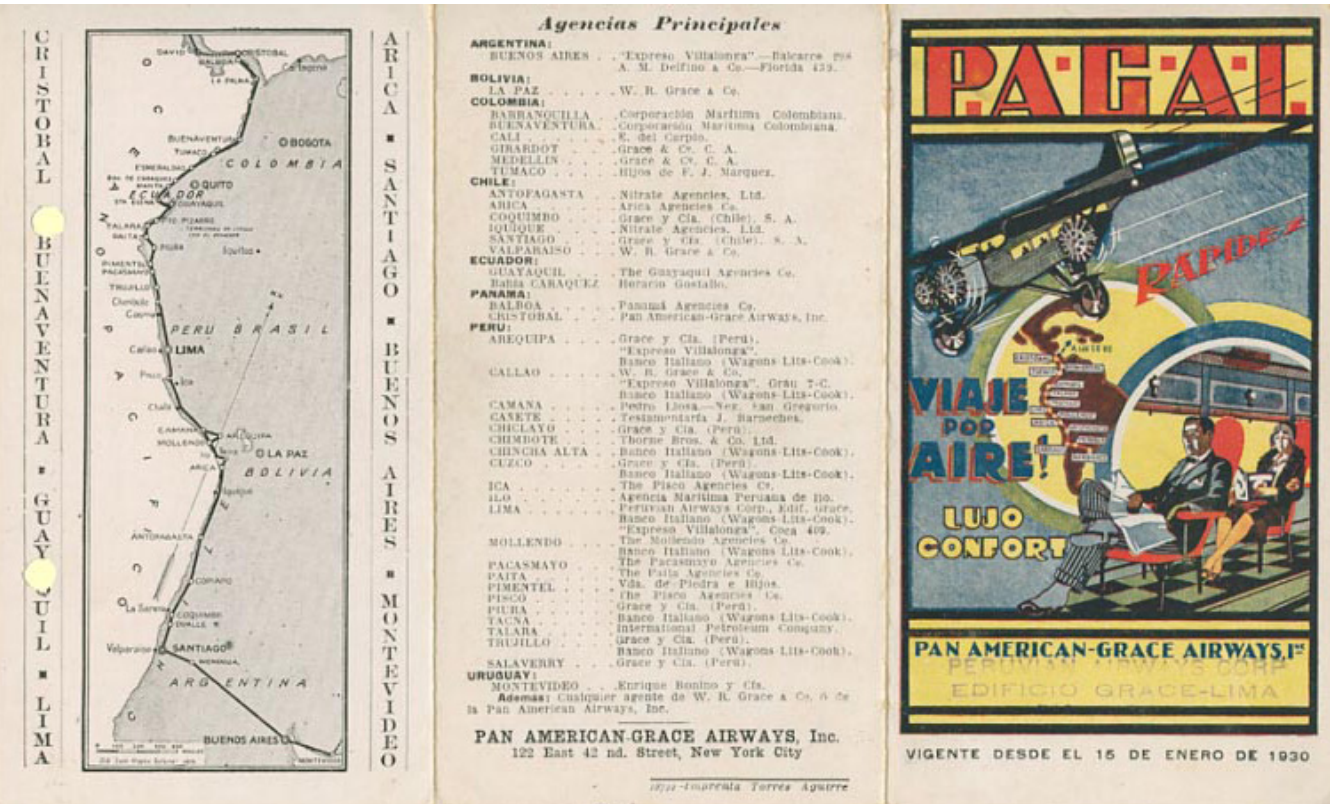

VIGENTE DESDE EL 15 DE ENERO DE 1030

y estimulaba este interés, entre otras formas a partir de la publicación de descripciones de "raids" y de otros viajes aéreos, que en muchos casos se acompañaban con fotografías de las aeronaves y de vistas aéreas. ${ }^{30}$ Esta difusión de la fotografía aérea enriquecía las imágenes del territorio nacional ${ }^{31}$ pero también aportaba

30. Véase ORTEMBERG, Pablo, "Los raids aéreos en los centenarios patrios de los años 20: aventuras latinoamericanistas y nacionalistas en el despegue de las rutas comerciales", mimeo.

31. Argentina, como otros países "nuevos" americanos, cifra en buena medida la nacionalidad en clave de territorio y paisaje. Véase, SILVESTRI, Graciela, "Postales argentinas", en ALTAMIRANO, Carlos (editor) La Argentina en el siglo XX, Ariel y Universidad Nacional de Quilmes, Bernal, 1999. a una cierta pedagogía del pasajero, que lo instruía sobre qué mirar, cómo apreciarlo, qué emociones eran deseables sentir frente al paisaje: el encuentro con esas "vistas" durante el viaje era, cada vez más, un re-encuentro con paisajes que ya se habían visto previamente o sobre los que se había leído. ${ }^{32}$ Un folleto de LASO de 1942 promovía su línea en esos términos: "Un vuelo de 8 horas inolvidable por el colorido y la grandiosidad de los panoramas que ofrece y demostrativo de la potencialidad nacional... le permite admirar desde el aire innumerables bellezas naturales como Nahuel

32. Véase por ejemplo COSGROVE, Denis y FOX, William, Photography and Flight, Reaktion Books Ltd., Londres, 2010, capítulo 2. 
Huapi, considerado una de las maravillas del mundo". ${ }^{33}$ Parte de los panoramas aparecían reproducidos en el propio folleto. Esta experiencia de la mirada aérea, entra además en juego con las miradas construidas por previas experiencias de movilidad "horizontales". Dice Tracol, "La Pampa y la Patagonia son hijas del viento. Cuando se las ve desde el cielo ello queda evidentemente demostrado. Sin embargo, para tener una idea completa de ello, hay que haber viajado en automóvil a través de las inmensas planicies argentinas". ${ }^{34}$

Cuando, con el progreso técnico, los aviones fueron ganando en altura y se desarrollaron sistemas de vuelo por instrumentos, se volvieron habituales otras experiencias. En primer término, la de atravesar las nubes, que deja por un tiempo a los pasajeros en un espacio sin referencias. "El avión -narra Antonio Crespi Valls, un periodista de Bahía Blanca que viajó en Aeroposta en 1940- ...En ciertos momentos atraviesa entre las nubes bajas. Se pierden de vista el cielo y la tierra. Estamos extraviados dentro de un celaje. Al rasgarse, aparecen campos, casas, arroyos, cascadas, encerradas en los recovecos de las montañas". ${ }^{35}$ Probablemente, respondiendo a las fantasías y temores que se proyectaban sobre las nubes, la revista de Aeroposta publicaba en 1939 varias notas explicándolas de un modo tal que quedaban asociadas casi exclusivamente al fenómeno del inocuo vapor de agua. ${ }^{36}$

\section{Folleto de LASO, Anexo de la Memoria de la} Agrupación Transportes, 1942, Archivo del Departamento de Estudios Históricos de la Fuerza Aérea Argentina.

34. “En avión...”, Op. Cit., p. 14.

35. Véase CRESPI VALLS, Antonio, "Volando de Bahía Blanca a Buenos Aires”, Revista Aeroposta, 1940, No 5, p.19.

36. Véase por ejemplo "Qué son las nubes.
Por el otro lado, la mayor potencia y altura y el cambio en los materiales de las aeronaves, van introduciendo distancias entre el pasajero y el aire: Crespi Valls, ${ }^{37}$ comparándola con los vuelos en los primeros aviones, describía la experiencia en el Junkers como de "inmovilidad": es tan escasa la percepción del movimiento, es tal el confort de los asientos, que si cierra los ojos, dice, puede imaginar que está "apoltronado" en tierra; la ausencia de cinturones de seguridad en el avión reforzaba esta percepción. ${ }^{38} \mathrm{~A}$ esto, se suma la atenuación del sonido de los tres motores: a los pasajeros se les entregan antes de despegar algodones para sus oídos (véase imagen 2).

Si desde la tierra, el aire aparece como un espacio sin superficies ni volúmenes, la experiencia de volar ofrece otras percepciones. Aunque los avances de la técnica fueron, desde los años treinta, incrementando la estabilidad y el confort, el distanciamiento con el medio es siempre transitorio: experiencias frecuentes como las de los pozos de aire, la turbulencia ${ }^{39}$ o las tormentas ponen en contacto al pasajero con las densidades, los movimientos, los volúmenes y concavidades del aire. Así, en el relato apacible de Crespi Valls se cuelan momentos de temor: "Me vuelve a la realidad la sensación de que el aparato, de golpe y

Consideraciones sobre la condensación del vapor de agua", Revista Aeroposta, 1939, No3, p.7.

37. Véase CRESPI VALLS, Antonio, "Volando de Bahía Blanca...", Op. Cit., p. 19.

38. En los primeros aviones, los monomotor sin techo rígido, por ejemplo, debía volarse amarrado con correas al asiento.

39. Los pozos de aire y otros tipos de turbulencias se producen por corrientes ascendentes o descendentes, generadas por calentamiento de la superficie de la tierra, por el viento o por la orografía. Estos fenómenos son menores cuando se vuela a gran altura. 
Imagen 3. LASO también entregaba algodones a sus pasajeros.

Fuente: Anexo de la Memoria de la Agrupación Transporte, 1942.

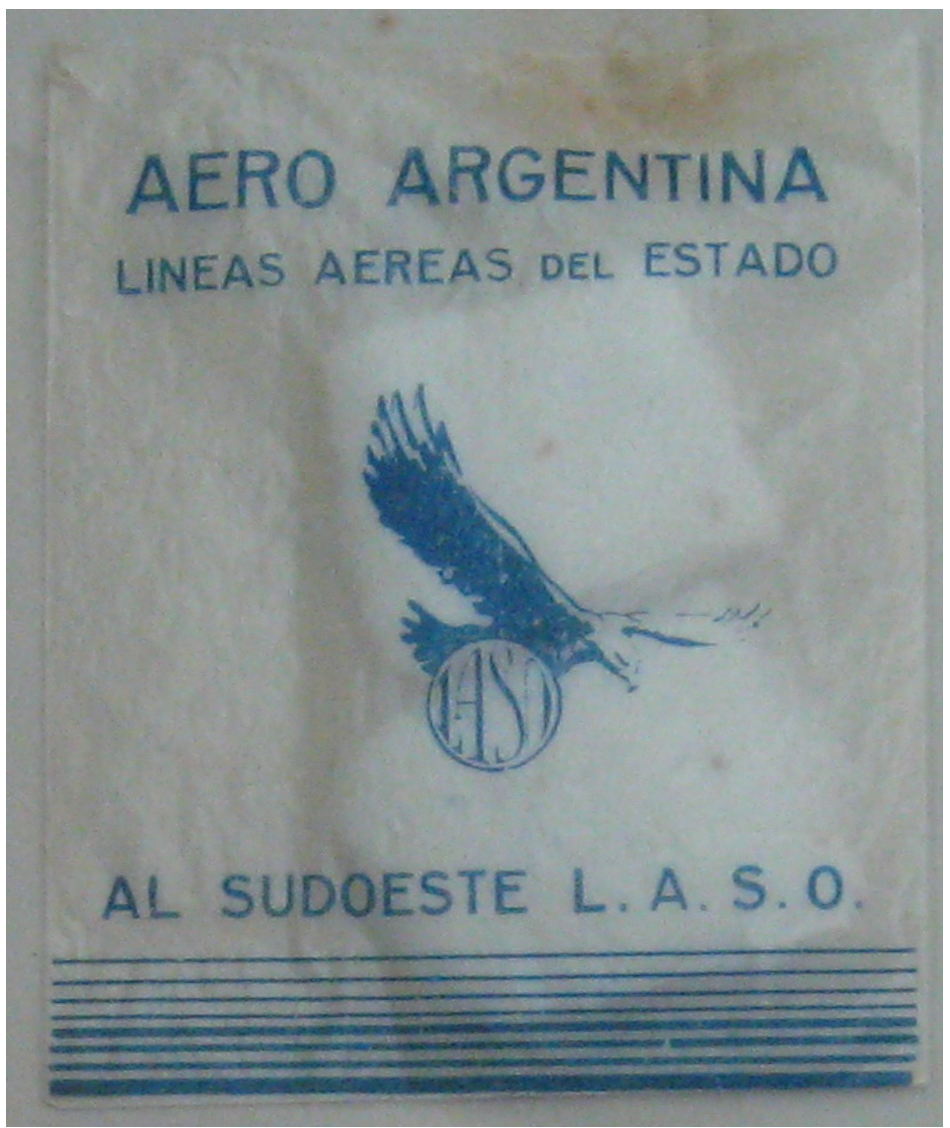

porrazo, se desploma. Materialmente siento que se cae como un peso muerto. Los pies se despegan del piso de la cabina y el cuerpo parece querer flotar, proyectado hacia arriba ¡Un pozo de aire!... Mientras cae el avión, quizás una fracción de segundo, el ruido característico de las hélices, pierden su ritmo. Se nota bien que las palas no 'muerden' el aire". ${ }^{40}$ La percepción angustiosa, física, de la caída, se matiza sin embargo, con la explicación tranquilizadora que reinserta al evento en un registro de normalidad: "todos sabemos que este fenómeno es equivalente a una gran ola en el mar". ${ }^{41}$ Frente a los temores del pasajero

40. Véase CRESPI VALLS, Antonio, "Volando de Bahía Blanca...", Op. Cit., p. 19.

41. Ibídem. 
debutante, quiénes vuelan frecuentemente -la mayoría-, que disponen ya de conocimientos acumulados sobre la práctica, no se alarman y se reponen de inmediato del percance: "Miro a los viajeros y, con excepción de dos o tres, los demás continúan como si tal cosa, leyendo o chupando naranjas ¡les tengo una envidia!". ${ }^{42}$

Pese a los cambios técnicos, entonces, las ansiedades y la falta de confort formaban parte inseparable de la experiencia de volar. El tema del mareo era una preocupación recurrente. Los compañeros de viaje de Crespi Valls debatían en el bar de la sala de espera de Bahía Blanca acerca de la mejor receta para evitarlo: el estómago vacío o la comida liviana. ${ }^{43}$ Los Junkers disponían, sobre cada asiento, de una "manguerita" con aire fresco para que los pasajeros se refresquen en caso de malestar. ${ }^{44}$ En algunos vuelos se les indicaba a los pasajeros que, en caso de náuseas, bajaran las ventanillas, que disponían de manivelas; unos años más tarde, en aviones con ventanillas fijas, las bolsitas para mareo se hicieron frecuentes. ${ }^{45}$ La ruta a la Patagonia, con vientos que superan los $100 \mathrm{~km} / \mathrm{h}$, resultaba particularmente exigente: los aviones eran- recuerda María Elena Murias, azafata de Aerolíneas entre 1957 y 1959- "una hoja al viento". Se trataba, ya a esa altura, de aviones DC-3, más confortables que los Junkers, con sanitarios y servicio de refrigerio liviano a bordo prestado por una azafata, pero en lo concreto las cosas

\section{Ibídem.}

43. Ídem, p. 18.

44. Ídem, p. 19.

45. Véase "Antesala de un posible accidente aéreo", s/d, Archivo privado Leopoldo Frenkel. Se trata de un relato anónimo de un viaje Río-Buenos Aires en 1938, con acuatizaje de emergencia, en un hidroavión Junker de la Corporación Cóndor (brasilera).

146 podían resultar bastante caóticas: "los vuelos al sur... lo terrible era que tenías veinticuatro pasajeros vomitando por toda la cabina, era algo impresionante... yo nunca me olvido de eso... No podías hacer ningún servicio, nada, tenías que quedarte atada, porque si no te estrellabas adentro del avión”. ${ }^{46}$

Al malestar estomacal se sumaban las molestias en los oídos, para las cuales, desde fines de los años cuarenta, las azafatas proveían a los pasajeros de caramelos masticables y chicles; probablemente el pasajero que chupaba naranjas, compañero ocasional de viaje de Crespi Valls, lo hiciera también para aliviar sus oídos. Algunos vuelos, como los que cruzaban la cordillera, eran aún más duros: hasta los años cincuenta, durante el cruce de los Andes los pasajeros debían recibir oxígeno.

Finalmente, las restricciones técnicas imponían otras incomodidades. Con aviones cuya cabina no se presurizaba, se volaba más bajo, por lo que aumentaba, junto a la turbulencia, el consumo de combustible. Esto sumado a una capacidad de carga menor, obligaba a programar escalas de frecuentes; así, por ejemplo, en 1947 el viaje de Buenos Aires a Río Gallegos incluía siete paradas. Esto extendía enormemente los tiempos del viaje: el vuelo a Río Gallegos, que salía de Buenos Aires los domingos y los jueves, demoraba unas 13 horas. Por otro lado, en las postas de reabastecimiento todo el pasaje debía descender por seguridad, ya que la "aeronafta" era mucho más inflamable que los combustibles actuales. ${ }^{47}$ Las escalas servían

46. Entrevista del autor a María Elena Murias, azafata de Aerolíneas Argentinas entre 1957 y 1960, 3 de mayo de 2014.

47. Véase POTENZE, Luciano, Aviación comercial argentina, Op. Cit., pp. 34 y 71. 
Imagen 4. Las azafatas de Fama, la empresa mixta destinada a vuelos internacionales. Circa 1948. Fuente: <http://loudandclearisnotenought.blogspot.com.ar/p/fama-flota-historica_11.html> [Consulta: marzo de 2015]

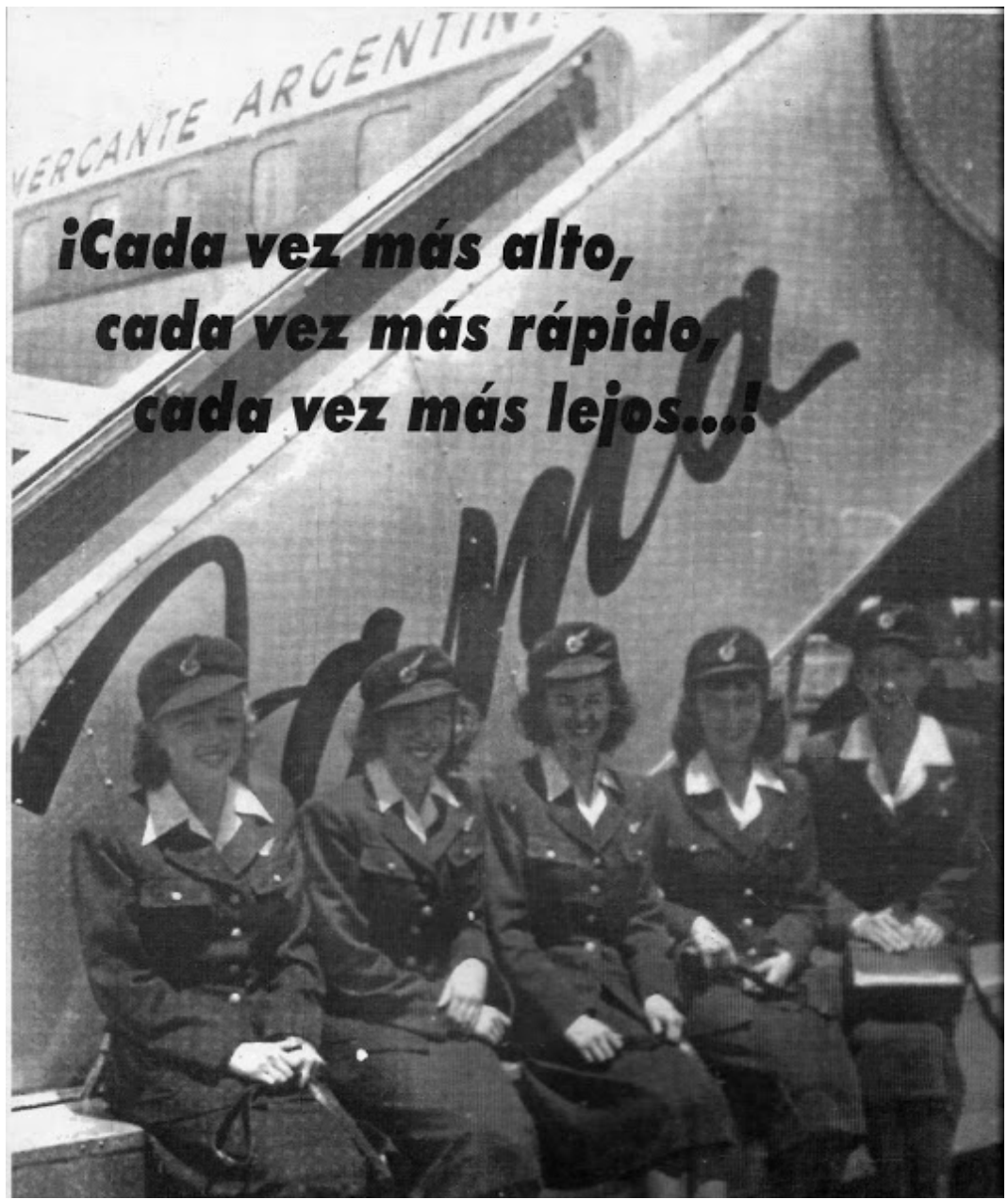

también para que los pasajeros pudieran comer o beber y utilizar los sanitarios, y algunos de ellos las experimentaban como momentos positivos de distención y sociabilidad. ${ }^{48}$ Los

48. Así lo refleja el autor anónimo de "Antesala de un vientos de la Patagonia demoraban a veces los vuelos, y muchas veces forzaban a los pasajeros $\mathrm{y}$ a las tripulaciones a pernoctar en las escalas (Aerolíneas no decolaba después de las 17 hs.,

posible...", Op. Cit. 
porque muchos de los aeropuertos argentinos no estaban preparados para operar de noche). ${ }^{49}$

La introducción de los asistentes de vuelo en la segunda mitad de los treinta -en los DC-3 y en algunos hidroaviones- buscó morigerar las incomodidades de los pasajeros y, a través de la oferta de refrigerios y de materiales de lectura, distraerlos de sus temores. Pero el papel de las azafatas iba, creemos, más allá. Al principio varones, luego mayoritariamente mujeres, en la Argentina el modelo de la azafata instruida, joven y elegante se impuso en la segunda mitad de los años cincuenta. ${ }^{50}$ Es posible pensar que la presencia de estas jóvenes atractivas y educadas establecía un tono, un umbral de cordialidad, calma y cortesía en torno al cual tendían a gravitar las interacciones sociales dentro del avión. Con una veintena de personas encerradas en un vehículo a miles de metros de altura, con potenciales situaciones de incomodidad, ansiedad o temor, los asistentes de vuelo podían haber resultado entonces un mecanismo para modelar y regular la conducta de los pasajeros, para transformarlos en cuerpos dóciles, de alguna forma paralelo a la reintroducción de los cinturones de seguridad. Murias refiere, así, por ejemplo, que, pese al temor de muchos pasajeros, predominaba la urbanidad: "Rezaban, tomaban el rosario, pero no hacían escándalo". 51

49. Entrevista a María Elena Murias, Op. Cit.

50. Las entrevistas de admisión de Aerolíneas en 1957, por ejemplo, hacían hincapié en la elegancia, la presencia, el bilingüismo y la capacidad de conversar sobre cuestiones de interés general. Entrevista de la autora a María Elena Murias, Op. Cit. La cuestión de las azafatas ha sido analizada desde perspectivas de género, sobre todo para el caso norteamericano. Véase por ejemplo BARRY, Kathleen, Femeninity in Flight, Duke University Press, Durham, 2006, capítulos 1 y 2.

51. Entrevista a María Elena Murias, Op. Cit.

\section{La "conciencia aeronáutica": las representaciones sobre la práctica}

La expansión del transporte de pasajeros dependió no solamente de las transformaciones técnicas que lo hicieron posible, sino también de que un número suficiente y creciente de personas se convenciera de que trasladarse de un lugar a otro volando en un avión era algo posible, seguro y deseable.

Viajar en avión era a principios de los años veinte percibido como algo ajeno, extraño y riesgoso, una práctica a la que se atrevían solamente los amantes de la aventura y las emociones fuertes. Sus cultores iniciales fueron miembros de la élite, modernos y ya fascinados con otros vehículos a motor, que se agruparon en una institución, el Aero Club Argentino (creado en 1908). Estas instituciones no se limitaban a facilitar las actividades de sus miembros, sino además que se asignaban a sí mismas una misión pública, basada en la profunda confianza en los beneficios de la modernización técnica y pensada a imitación de las naciones europeas y de los Estados Unidos. Así, los dirigentes del Aero Club Argentino impulsaron en 1912 la creación de la Escuela de Aviación Militar, que dependía del Ejército y funcionó durante algunos años con el parque aerostático y los profesores del Club. En la primera posguerra, la competencia entre las compañías europeas por imponer sus aviones y apropiarse de las rutas comerciales americanas se combinó con la pasión deportiva y se multiplicaron los raids y los récords, reproducidos en detalle por los periódicos. ${ }^{52}$

52. Véase ORTEMBERG, Pablo, "Los raids aéreos...", Op. Cit; MARTÍNEZ, Salvador Roberto, Aquellos

Precursores, Dunken, Buenos Aires, 2013. 
Los aeroclubes se fueron replicando en el interior del país a lo largo de los años siguientes. Desempeñaban funciones cruciales, como el entrenamiento de pilotos civiles y la construcción de muchos de los aeródromos que hicieron posible la expansión inicial del aerotransporte en la Argentina. También tuvieron un papel clave en la construcción de lo que en la época se conocía como "conciencia aeronáutica", la adhesión a la aeronavegación como transporte del futuro, como fascinante símbolo de modernidad, que debía traducirse en un movimiento en favor de la creación de las condiciones necesarias para su difusión. Los aeroclubes organizaron exhibiciones de destreza aérea y de maquinaria, festivales, cursos, vuelos de bautismo, y participaron también a nivel local como parte de las "fuerzas vivas" de la comunidad, contribuyendo a despertar intereses y vocaciones y a estimular el entusiasmo general por la aviación. Estas y otras instituciones y organizaciones ligadas a la aviación civil comenzaron a mediados de los años veinte a organizarse y a unirse para interpelar a la opinión pública y al Estado. Así, por ejemplo, a principios de los años treinta tuvieron lugar las primeras conferencias nacionales de aeronáutica, laboratorio de buena parte de la legislación aeronáutica argentina.

El interés creciente por los aviones estimuló el surgimiento de revistas dirigidas a la "afición" por los transportes modernos, como Auto aérea (1920-1928), o la más moderna Transportes y Comunicaciones (1929-1931), que sostenía que en los transportes modernos se jugaba para la Argentina la posibilidad de estar entre las naciones adelantadas del mundo. ${ }^{53}$

53. Véase Anuncio editorial, Revista Transportes y Comunicaciones, 1930, s/n.
De modo más general, la prensa, el cine y la radio alimentaban esta pasión modernista, que unía el cambio técnico y la velocidad, al progreso del país. La aviación es una de las tecnologías que circulaban profusamente en la prensa popular en la entreguerra: en diarios, revistas, manuales, o publicaciones de divulgación. ${ }^{54} \mathrm{La}$ mirada sobre ellas era mayoritariamente optimista y se buscaba "anticipar más porciones de ese futuro que parece deseable y del que no se piensa que la Argentina esté excluida”. ${ }^{55}$ Así, por ejemplo, en 1944, el Automóvil Club Argentino imaginaba que en la segunda posguerra el turismo se basaría en una combinación de aviones particulares y automóviles y planificó la construcción de una veintena de estaciones de servicio "aéreas-camineras", para prestar servicio a esos vuelos. ${ }^{56}$

Esta difusión fue generando una familiaridad con el avión, una confianza en esa tecnología como algo que podía transportar personas de modo regular. En la Argentina, esto se vio ayudado por la ausencia de accidente $s$ graves entre la segunda mitad de los años treinta y mediados de los años cuarenta. Si bien los mismos se incrementaron notablemente cuando aumentó el tráfico (entre 1950 y 1959 se registraron 13 siniestros en vuelos de cabotaje, con decenas de víctimas fatales) esto no parece haber repercutido demasiado en la difusión de la práctica del viaje aéreo, ya que el número de pasajeros continuó creciendo de forma acentuada a lo largo del período.

54. Véase SARLO, Beatriz, La imaginación técnica. Sueños modernos de la cultura argentina, Nueva Visión, Buenos Aires, 1992, p. 69.

55. Ídem, p.81.

56. Véase Revista Automovilismo, 1944, p.77. 
En algunas regiones, como en la Patagonia, el avión, que desempeñaba funciones fundamentales de comunicación, tenía una alta valoración social. Así, por ejemplo, en 1931 las poblaciones del sur encabezaron los reclamos para que el Estado asegurara la continuidad del servicio de Aeroposta amenazado por la quiebra $\mathrm{y}$, en los años cuarenta, reclamaron que se concedieran a la empresa nuevas rutas en la región. ${ }^{57}$ En la Patagonia, sostenía en 1940 la revista de la empresa que se distribuía ampliamente en la región, "diez años de convivencia con la Aeroposta han producido ese estado de comprensión y fe en la aviación que hace que sus habitantes empleen para sus viajes el avión con la misma naturalidad que si se tratase del tren o el automóvil". ${ }^{58}$ Como ejemplo de esa "conciencia aeronáutica", que la revista se proponía estimular, la nota se ilustraba con la foto de un grupo de jovencitas residentes de Tierra del Fuego y alumnas de colegios en Buenos Aires, "cuyos padres las confían al avión con la misma tranquilidad que si las enviasen por barco. Es decir, no, con mayor tranquilidad, porque en avión el viaje solo dura horas, mientras que por mar son ocho o diez días de preocupación para los familiares". ${ }^{59}$

57. En 1939, el Congreso General de Territorios Nacionales, aprobó un proyecto de declaración y un informe a favor de la extensión de la línea de Comodoro hacia el oeste de Santa Cruz y hacia Punta Arenas en Chile. La Revista recordaba que cuando la línea amenazó suspenderse en 1931 el clamor de los pueblos patagónicos fue tal que el gobierno hubo de oír y auxiliarla para que siguiese. Véase "Un anhelo y una necesidad de Pueblos de la Patagonia austral”, Revista Aeroposta, 1939, № 3, pp. 18-20.

58. Véase. “¿Ha viajado Ud. ya en avión?”, Ibídem, p. 42.

59. Ibídem.
La "fe" en la aviación, se cimentaba en algunos elementos. La seguridad era, por supuesto, una cuestión clave en la propaganda de Aeroposta y de otras aerolíneas y se centraba en general en torno a la modernidad de las máquinas. La revista de Aeroposta, insistía sobre la tecnología de punta de sus aviones como garantía de seguridad, describiendo minuciosamente los detalles técnicos de los Junkers o de las instalaciones de radio y sus ventajas. ${ }^{60}$ Cuando la confianza pública en los aviones como artefactos de transporte probados y no "experimentales" se asentó, la publicidad al respecto comenzó a enfatizar también el profesionalismo de los pilotos: así por ejemplo, la publicidad de LASO en 1942 destacaba "Tripulación experta y aviones ultramodernos". ${ }^{61}$

La revista de Aeroposta publicaba también una sección específica, “¿Ha viajado Ud. ya en avión?”, dedicada a estimular la aceptación del nuevo medio de transporte y que enfatizaba la cuestión de la seguridad. “¡Cuán equivocados están los que aún creen que viajar por el aire es más peligroso que viajar por tierra!", se lamentaba la revista en 1940, mientras afirmaba que había mayor riesgo en cruzar una calle del centro de Buenos Aires o en abordar un colectivo que en subirse a un avión. ${ }^{62}$ Como en el caso de las escolares, se insistía en que la velocidad de las máquinas acortaba los tiempos, y reducía también los riesgos, que eran, de todos modos, inherentes a cualquier

60. Véase por ejemplo "Por qué se viaja con seguridad en los Junkers de Aeroposta”, Revista Aeroposta, 1939, № 1, pp. 22-24; "Radio, ojos y oídos de los aviones", Revista Aeroposta, 1941, o 11, p. 13.

61. Véase folleto de LASO, Op. Cit.

62. Véase. “¿Ha viajado Ud. ya en avión?”, Revista Aeroposta, 1940, No 5, p. 15. 
Imagen 5. Publicidad de la CSTA, principios de los años cuarenta. Fuente: <http://www.eldiario.com.ar/extras/impresa/imprimir.php?id=106460 > [Consulta: marzo de 2015]

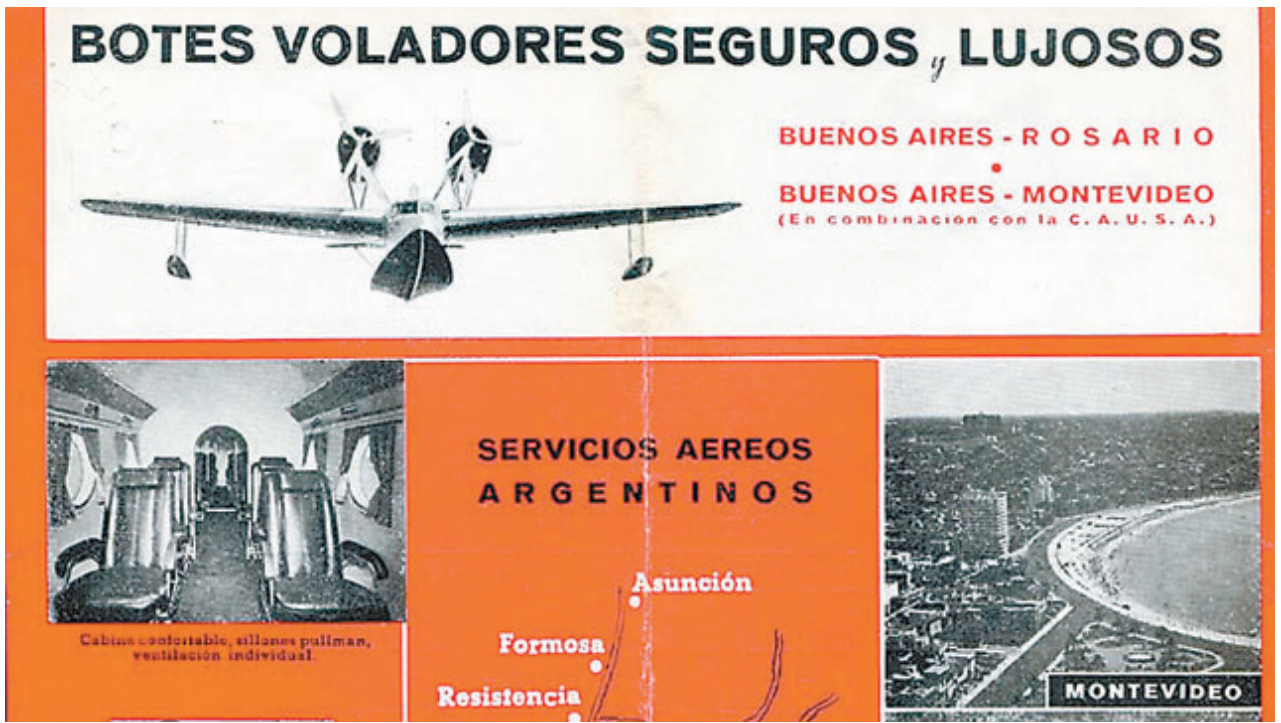

medio de transporte, "La seguridad es algo relativo... la verdadera seguridad no existe en este mundo". ${ }^{63}$

La revista también publica fotografías de pasajeros, a las que acompañaba una pequeña historia; los relatos permitían al lector identificarse con estas personas ordinarias e imaginarse a sí mismo, pasajero. Así, por ejemplo, en 1938, se publicó la fotografía comentada de un hombre con ropa de campo, un hombre "de tierra adentro", arribando en Buenos Aires. "Tratábase de una gran urgencia, y por ello no ha vacilado en dejar, por primera vez, a su fiel caballo... y... se ha "largado" en avión. Acaba de terminar el viaje y él ha

63. Véase “¿Ha viajado Ud....?”, Op. Cit., p. 21. quedado muy satisfecho del experimento... El Progreso, en su manifestación más terminante, la aviación, lo acaba de ganar para siempre! ...Sin duda habrá echado de menos a su caballo, pero... Ha quedado tan contento de constatar lo rápido, cómodo y seguro que se viaja en avión...!". ${ }^{64} \mathrm{Si}$ la seguridad fue un argumento clave a la hora de persuadir a los potenciales pasajeros, la velocidad, el dramático acortamiento del tiempo, era sin duda el elemento más competitivo: quienes necesitaban viajar con premura, como el hombre de campo de la historia, se arriesgaban a algo que a muchos todavía les generaba ansiedades.

64. Véase. "Nuevas conquistas del progreso", Revista Aeroposta, 1938, № 2, p. 19. 
Imagen 6. Publicidad de LADE, 1945.

Fuente: Archivo del Departamento de Estudios Históricos de la Fuerza Aérea Argentina

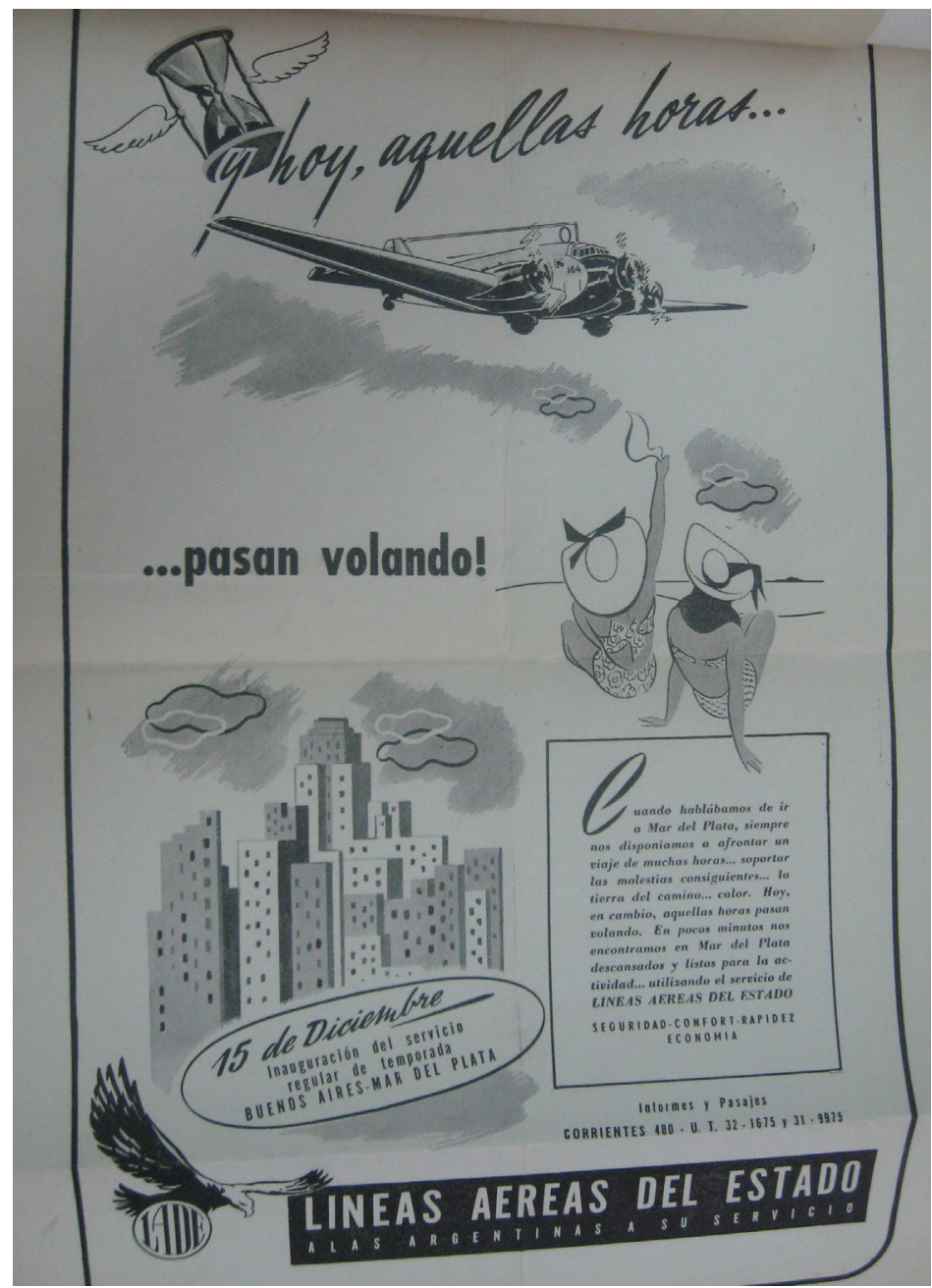

Algo más tardías, las publicidades de las líneas del Estado de 1945 ligaban la velocidad del viaje no ya a la urgencia, sino al placer. Un folleto del Parque Nacional Nahuel Huapi, recordaba que con la instalación de LASO "los hombres de negocios y los turistas internacionales que no disponen de tiempo para invertir en largos viajes" podían visitar, tras unas horas de un viaje placentero, el Parque Nahuel Huapi. ${ }^{65}$ Del mismo modo, se

65. Inserto sobre LASO en un Folleto de difusión del Parque Nacional Nahuel Huapi, Anexo de la Memoria 
publicitaba la recién inaugurada línea a Mar del Plata, en 1945: "Cuando hablábamos de ir a Mar del Plata, siempre nos disponíamos a afrontar un viaje de muchas horas... soportar las molestias consiguientes... la tierra del camino... calor. Hoy, en cambio, aquellas horas pasan volando. En pocos minutos nos encontramos en Mar del Plata, descansados y listos para la actividad" (véase imagen 6). ${ }^{66}$

La construcción del viaje en avión como un consumo, implicó además, que éste fuera no sólo conveniente y seguro, sino también deseable. El avión se asociaba a la modernidad y a la emoción. Brillante conquista en el progreso técnico de la humanidad, generaba una amplia afición, alimentada por las películas norteamericanas, la literatura de difusión, la prensa y hasta por los juguetes infantiles, como los aviones de hojalata pintada que la empresa Matarazzo fabricaba en Argentina en los años treinta. ${ }^{67}$ Las aerolíneas alentaban esta asociación entre avión y modernidad, sobre todo en los años en que aún había que vencer los fuertes temores de los potenciales viajeros. En noviembre de 1934, la revista de Aeroposta afirmaba: "E1 no haber viajado en avión nos coloca algo así como en un estado de inferioridad ante a los que lo utilizan... Hay que ser de su época... No lo será Ud. completamente mientras no haya viajado $\mathrm{Ud}$. en avión”. ${ }^{68}$

de la Agrupación Transportes, 1942, Archivo del

Departamento de Estudios Históricos de la Fuerza Aérea Argentina.

66. Publicidad de LADE, verano 1945, en Circulares internas de LADE, 1945, Archivo Departamento de Estudios Históricos de la Fuerza Aérea.

67. En algunas de estas películas, como "Flying Down to Rio” (1933), los aviones aparecían como parte de las aventuras de personajes distinguidos y llenos de glamour. 68. “¿Ha viajado Ud....?”, Op. Cit., p. 21.
El viaje en avión se construyó también como una práctica distinguida. La Compañía Sudamericana no sólo presentaba a sus hidroaviones como seguros, sino también los señalaba como "lujosos", mismo término al que apelaban las publicidades de Panagra en sus publicidades desde 1930 (Véase imágenes 2 y 5). Viajar en avión, como vacacionar en Mar del Plata, era un práctica deseable de exhibir: como en la Rambla marplatense, en Ezeiza un fotógrafo se dedicaba a retratar en la escalerilla a quienes descendían del avión; reveladas rápidamente en un espacio dentro del propio aeropuerto, las fotos eran vendidas a los pasajeros, como souvenir, antes de que dejaran el aeropuerto. ${ }^{69}$

La distinción era también un efecto brindado por las restricciones de acceso. Pese al número creciente de pasajeros, viajar en avión era una actividad costosa y que sólo podía afrontarla una minoría. Lo usual era que muchos fueran viajeros frecuentes. En los vuelos a Europa, relata Murias, buena parte de los pasajeros se repetían año tras año, como una familia de empresarios chocolateros, que viajaba en las literas del DC-6 y repartía en cada ocasión bombones entre el personal de Aerolíneas. ${ }^{70}$ En los vuelos a la Patagonia, o al Litoral, el "pasajero frecuente" era un fenómeno aún más habitual. ${ }^{71}$

La distinción de la práctica se construía también en ese encuentro entre quienes podían reconocerse como pares sociales y culturales (o distinguir a quién no lo era y sólo iba a mirar),

69. Entrevista de la autora a Laura Quesada de Rivarola, azafata de Aerolíneas Argentinas entre 1957 y 1960, 3 de mayo de 2014.

70. Entrevista a María Elena Murias, Op. Cit.

71. Entrevista a Laura Quesada de Rivarola, Op. Cit. 
Imagen 7. Foto-souvenir, 1957. El fotógrafo de Ezeiza solía regalarles copias a las azafatas. Fuente: Archivo María Elena Murias

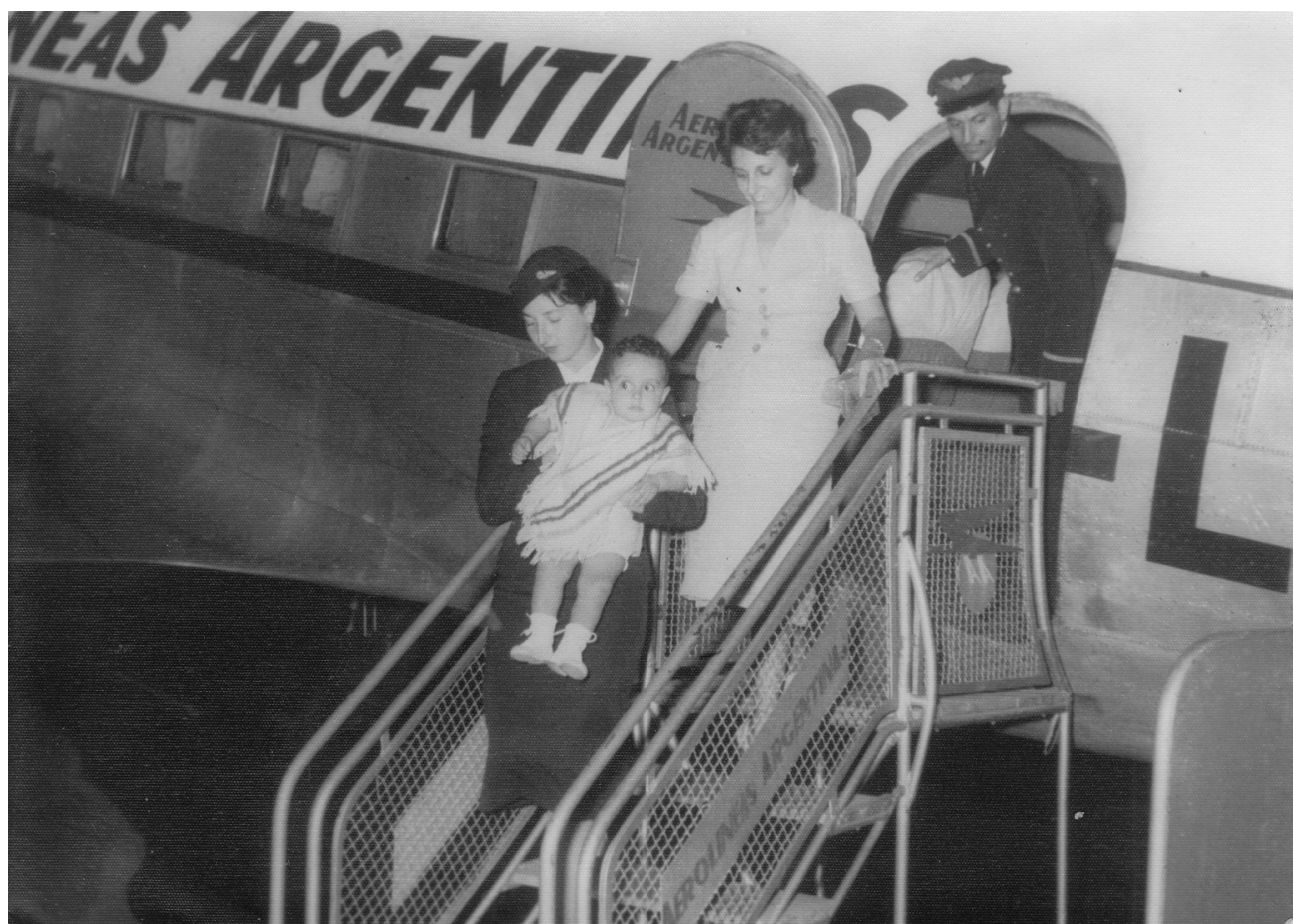

en medio de un consumo suntuario, en el avión o en el espacio familiar del aeropuerto. A diferencia de fenómenos masivos como los de la terminal de Pan American en Miami en los años cuarenta, ${ }^{72}$ los aeropuertos argentinos de la primera mitad del siglo XX eran espacios familiares, de una escala reducida y donde era posible que pasajeros y empleados se reconocieran, además de funcionar como

72. Véase VAN VLEK, Jenifer, Empire of the Air. Aviation and the American Ascendancy, Harvard University Press, Boston, 2013, Introduction. espectáculo para quienes no podían volar pero compartían la fascinación por los aviones. ${ }^{73}$ Ezeiza y Aeroparque, disponían de terrazas de acceso público para contemplar despegues y aterrizajes (véase imágen 7 ). ${ }^{74}$

73. Entrevista a Laura Quesada de Rivarola, Op. Cit.

74. Véase BALLENT, Anahí, “El peronismo...”, Op. Cit.; Esta es una dimensión completamente eliminada de los aeropuertos modernos. Véase CWERNER, Saulo, "Introducing...", Op. Cit., p.8. 
Imagen 8. Aeroparque Jorge Newbery (Buenos Aires), 1962.

Fuente: Fototeca Archivo General de la Nación.

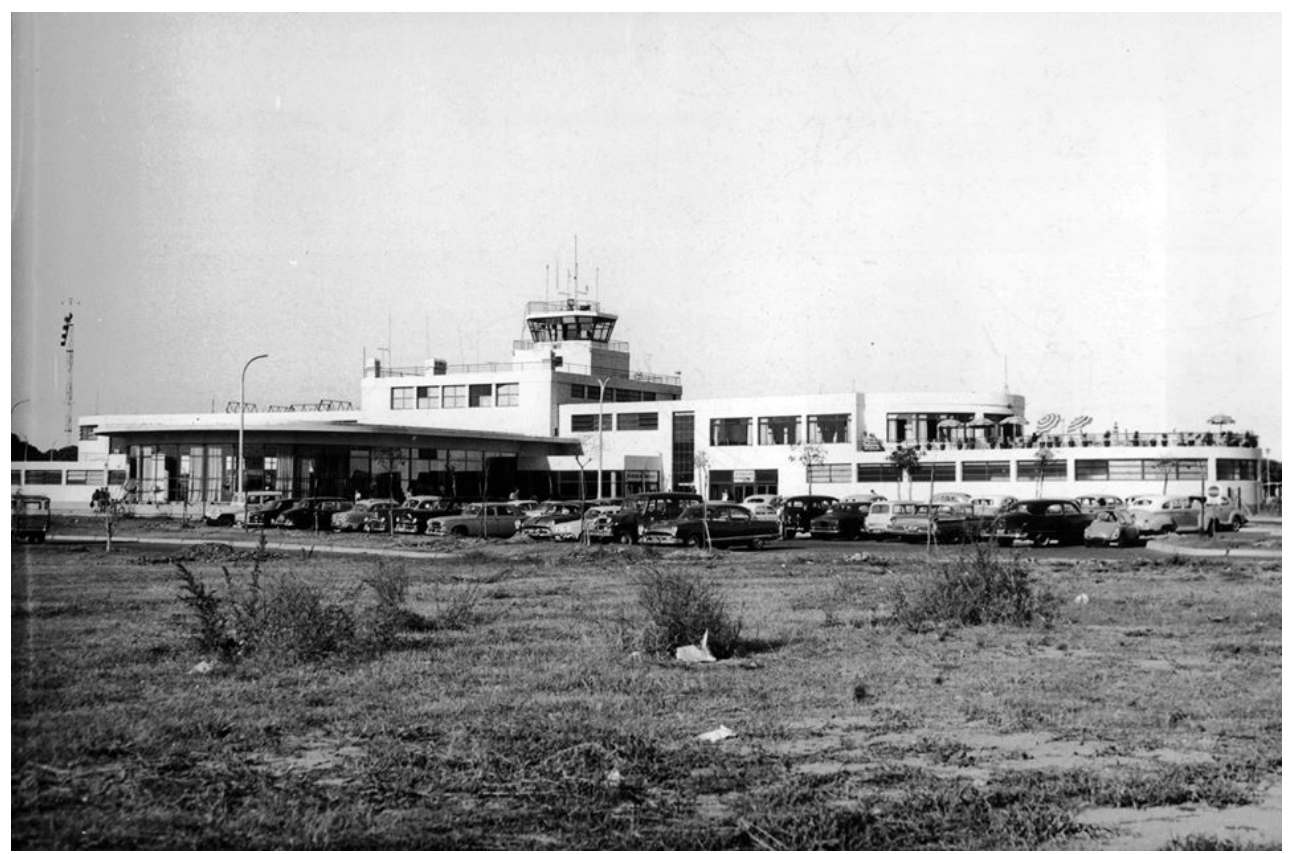

\section{Conclusiones}

En medio de aceleradas innovaciones tecnológicas, en poco más de una década, los aviones se establecieron como medios de transporte regular de pasajeros. En la base del desarrollo del transporte aéreo de pasajeros están, por supuesto, los cambios técnicos que aumentaron el tamaño y la carga útil. Hemos procurado mostrar también, a través de la historia de las aerolíneas en la Argentina, que esos cambios impactaron de forma mediatizada en el consumo, dando cuenta de las complejidades de los vínculos entre la tecnología, el espacio y las lógicas económicas y políticas, que en su conjunto determinaron, finalmente, las condiciones materiales para el transporte de pasajeros en Argentina. Así, por ejemplo, durante los años cuarenta y cincuenta, la conjunción de una serie de circunstancias (las características demográficas del país, la nacionalización de la infraestructura de tierra y la lenta construcción de aeropuertos, las dificultades para importar aviones nuevos) llevaron a que el tráfico aéreo de cabotaje continuara realizándose con una tecnología previa a la Segunda Guerra que determinaba volar bajo y llevar pocos pasajeros. Esto 
implicaba una serie de incomodidades para aquellos últimos (turbulencias, múltiples escalas) y encarecía las tarifas, pero, a la vez, como esas máquinas no requerían aeródromos sofisticados, permitía que ciudades menores (que hoy no poseen este servicio) tuvieran transporte aéreo regular, aumentando la distribución geográfica de los pasajeros y el contacto de esas poblaciones con la cultura del avión.

Como hemos visto, entonces, aún con los avances técnicos, hasta los años sesenta en la Argentina, la experiencia de volar implicaba para los pasajeros una dosis variable, pero siempre presente, de incomodidad física. Sin embargo, resultaba emocionante y placentero en otros aspectos (desde la sociabilidad en las escalas hasta el placer estético), amén de conveniente, por la economía de tiempo que ofrecía y, entre 1938 y 1948, ciertamente muy seguro. Por otra parte, las molestias resultaban más tolerables, a medida que los propios usuarios aprendían a ser pasajeros de avión.

Construir a los pasajeros como nuevos sujetos consumidores conllevó el aprendizaje de una serie de comportamientos, de disposiciones corporales, anímicas y mentales: la espera en el aeropuerto y durante las escalas, ciertas formas de respirar para manejar las sensaciones del despegue, las náuseas o el mareo, las maniobras para destapar los oídos, la forma de comportarse frente a los "saltos" del avión en caso de turbulencia, lo que era posible y conveniente llevar en la cabina (caramelos, chicles o naranjas). Incluyó también la elaboración de mecanismos de regulación y disciplinamiento de los cuerpos en el aire, un proceso en el cual las azafatas desempeñaron un papel central. Finalmente, la construcción de la práctica del viaje en avión supuso un entrenamiento de la percepción (y de la capacidad de extraer goce de esa experiencia), anticipado por las fotografías aéreas difundidas en la prensa y la publicidad, que estimuló la imaginación geográfica y la emoción patriótica.

Por último, hemos señalado que, en el sustrato de la disposición de los posibles pasajeros a consumir esa experiencia, se encuentra la emergencia de un universo de ideas, valores, actitudes, instituciones y prácticas alrededor del avión, que crearan un sentimiento más o menos amplio de aceptación y familiaridad, lo que sus defensores llamaban una "conciencia aeronáutica”. Análogo y apenas posterior a los procesos de emergencia de una cultura en torno al automóvil, este proceso transformó la percepción del viaje en avión como extraño, incómodo y atemorizante, en una práctica prestigiosa, segura, deseable, moderna y distinguida entre quienes volaban y también entre quienes jamás podrían hacerlo. ${ }^{75}$

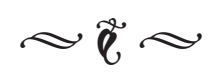

Recibido: 27-05-2015 Aceptado: 11-09-2015 Publicado: 21/12/2015

75. Véase por ejemplo, FEATHERSTONE, Mike, THRIFT, Nigel y URRY, John, Automobilities, SAGE, Londres, 2005; GIUCCI, Guillermo, La vida cultural del automóvil. Rutas de la modernidad cinética, Universidad nacional de Quilmes Editorial y Prometeo 3010, Bernal, 2007. 


\section{Bibliografía}

ALIATA, Fernando y SILVESTRI, Graciela, El paisaje en el arte y las ciencias humanas, CEAL, Buenos Aires, 1994.

APPADURAI, Arjun (editor) La vida social de las cosas. Perspectiva Cultural de las mercancias, Grijalbo, México, 1986.

BALLENT, Anahí, "El peronismo y sus escenarios. La operación territorial de Ezeiza (1944-1955)”, en Entrepasados, Buenos Aires, 2002, No 22, pp. 7-25.

BARRY, Kathleen, Femeninity in Flight, Duke University Press, Durham, 2006.

BEDNAREK, Janet R., "Open Sky: The Broad Range of Recent Scholarship in Aviation History”, en Movilidad en la Historia, Anuario de la Asociación Internacional de Historia del Transporte, el Tráfico y la Movilidad, Philadelphia, 2013, V. IV, pp. 89-94.

BOCOCK, Robert, El Consumo, Talasa, Madrid, 1993.

COSGROVE, Denis y FOX, William, Photography and Flight, Reaktion Books Ltd., Londres, 2010.

CWERNER, Saulo, "Introducing Aeromobilities", en CWERNER, Saulo, KESSERLING, Sven y URRY, John (editores) Aeromobilities, Rutledge, Nueva York, 2009.

FEATHERSTONE, Mike, THRIFT, Nigel y URRY, John, Automobilities, SAGE, Londres, 2005.

GIUCCI, Guillermo, La vida cultural del automóvil. Rutas de la modernidad cinética, Universidad nacional de Quilmes Editorial y Prometeo 3010, Bernal, 2007.

LURO CAMBACERES, Rufino, Rumbo 180․ Huellas en el cielo austral, Buenos Aires, 1956.

MARTÍNEZ, Salvador Roberto, Aquellos Precursores, Dunken, Buenos Aires, 2013.

MASEFIELD, Peter, "From Paris to Chicago. The Civilisation of Air Transport”, en The Putnam Aeronautical Review, Londres, 1990, V. II, pp. 18-23.

MILANESIO, Natalia, Cuando los trabajadores salieron de compras. Nuevos consumidores, publicidad y cambio cultural durante el primer peronismo, Siglo XXI, Buenos Aires, 2014.

MINISTERIO DE CULTURA Y EDUCACIÓN, “Evolución de los salarios docentes. 1906-1975”, 1976, disponible en: <http://repositorio.educacion.gov.ar/dspace/bitstream/handle/123456789/91821/ EL001296.pdf ?sequence $=1>$ [Consulta: 23-3-2015]

ORTEMBERG, Pablo, "Los raids aéreos en los centenarios patrios de los años 20: aventuras latinoamericanistas y nacionalistas en el despegue de las rutas comerciales”, mimeo. 
PASTORIZA, Elisa, La conquista de las vacaciones. Breve historia del turismo en la Argentina, Edhasa, Buenos Aires, 2011.

PÉREZ, Inés, El hogar tecnificado, Biblos, Buenos Aires, 2013.

PHILLIPS NEWTON, Wesley, “International Aviation Rivalry in Latin America, 1919-1927”, en Journal of Inter-American Studies, 1965, V. VII, No 3, pp. 346-352.

HAGEDORN, Dan, Conquistadors of the Sky. A History of Aviation in Latin America, Florida University Press, Gainsville, 2010.

PIGLIA, Melina, Autos, rutas y turismo. El Automóvil Club Argentino y el Estado, Siglo XXI, Buenos Aires, 2014.

PIRIE, Gordon, "Incidental Tourism: British Imperial air travel in the 1930's", en Journal of Tourism History, Preston, 2009, V. 1, No 1, pp. 49-66.

POTENZE, Luciano, Historia del Transporte Aerocomercial, mimeo, s/n.

ROCCHI, Fernando, "Inventando la soberanía del consumidor: publicidad, privacidad y revolución del mercado en Argentina, 1860-1940”, en DEVOTO, Fernando y MADERO, Marta (directores) Historia de la vida privada en Argentina, T. II, Taurus, Buenos Aires, 1999, pp. 301-321.

SARLO, Beatriz, La imaginación técnica. Sueños modernos de la cultura argentina, Nueva Visión, Buenos Aires, 1992.

SILVESTRI, Graciela, "Postales argentinas", en ALTAMIRANO, Carlos (editor) La Argentina en el siglo XX, Ariel y Universidad Nacional de Quilmes, Bernal, 1999, pp. 111-135.

VAN VLEK, Jenifer, Empire of the Air. Aviation and the American Ascendancy, Harvard University Press, Boston, 2013. 